\title{
HIV RISK BEHAVIOUR KNOWLEDGE, SUBSTANCE USE AND UNPROTECTED SEX IN MEN WHO HAVE SEX WITH MEN IN TALLINN, ESTONIA
}

\author{
A Tripathi ${ }^{1}$, K Rüütel $^{2}$, R D Parker (David.Parker@uscmed.sc.edu) ${ }^{1}$ \\ 1. University of South Carolina, School of Medicine, Columbia, South Carolina, United States \\ 2. Department of Infectious Diseases and Drug Abuse Prevention, National Institute for Health Development, Tallinn, Estonia
}

This article was published on 9 December 2009.

Citation style for this article: Tripathi A, Rüütel K, Parker RD. HIV risk behaviour knowledge, substance use and unprotected sex in men who have sex with men in Tallinn, Estonia. Euro Surveill. 2009;14(48):pii=19429. Available online: http://www.eurosurveillance.org/ViewArticle.aspx?ArticleId=19429

\begin{abstract}
This study examines HIV risk behaviour knowledge, substance use and unprotected sex in a sample of 79 men who have sex with men (MSM) in Tallinn, Estonia. Median age of the study population was 30 years (range 18-62 years); 35 were bisexual; 56 answered correctly to at least 10 out of 13 questions about HIV risk behaviors; 23 consumed more than seven alcoholic drinks in the week before the survey; nearly half $(n=34)$ of the participants reported some illicit drug use in the past 12 months; 40 did not use a condom regularly in the 12 months preceding the survey, and 41 did not use a condom during their last sexual intercourse. Alcohol consumption in the week before the survey was negatively associated with condom use during last intercourse (RR 0.48; 95\% Cl 0.41-0.56). Use of illicit drugs varied significantly by ethnicity ( $p$-value $=0.02$ ). Multivariable analysis showed that higher consumption of alcohol in the week before the survey could be predicted by education, age group and sexual orientation. In conclusion, socio-demographic factors such as education, age, ethnicity and sexual orientation may affect HIV risk behavior knowledge, sexual behavior and substance use among MSM in Estonia, and need to be taken into consideration for targeted HIV prevention.
\end{abstract}

\section{Introduction}

Since 2001, HIV prevalence has increased rapidly in Russia and Eastern Europe. Between 2001 and 2007, countries in Eastern Europe experienced a $150 \%$ increase in newly diagnosed HIV infections, a much larger increase than other European regions [1]. Of the former Soviet republics, Estonia has experienced the largest increase in the estimated HIV prevalence [2]. In 2008, Estonia had the highest number of newly diagnosed cases of HIV per million population (406/ million) among 28 out of 30 European Union (EU) and European Economic Area (EEA) countries [3]; and in 2007, the second highest estimated HIV prevalence, with over $1 \%$ of the adult population infected [4]. In Estonia, the HIV epidemic is mainly attributed to needle sharing among injecting drug users (IDU) and consequently, over the past decade, most research and HIV prevention has targeted IDU $[5,6]$.

In Eastern Europe the HIV epidemic is mainly concentrated among IDU and commercial sex workers and their respective sexual partners, whereas overall in EU/EEA, unprotected sex between men continues to remain the predominant mode of HIV transmission $[3,7]$. In recent years, newly diagnosed HIV cases among men who have sex with men (MSM) have increased in several Western European countries [3, 8, 9]. In Central Europe, the predominant mode of transmission is heterosexual contact, although reported HIV cases among MSM have increased rapidly over the past few years [10]. According to the European Center for Disease Prevention and Control (ECDC) and World Health Organization's (WHO) report on HIV/AIDS surveillance in Europe for 2007, more than half of the newly diagnosed cases of HIV infection were reported among MSM in Central European countries such as the Czech Republic, Slovenia, Slovakia, Croatia and Montenegro [2]. MSM are at risk of exposure to HIV for various reasons which may be facilitated by stigmatization $[11,12]$. In Eastern Europe, gay communities are newly established compared with their Western counterparts, which may be an impediment for peer-driven prevention strategies [13]. Limited research has been published on HIV risk behavior among MSM in Estonia [6]. To facilitate preventive policies towards maintaining lower HIV prevalence among MSM, there is a need to understand risk behavior in relation to socio-demographic and behavioural characteristics. Our study aims to explore the relationship of socio-demographic and behavioral characteristics with HIV risk behaviour knowledge, substance use and unprotected sex among MSM in Tallinn, Estonia.

\section{Methods}

Our study uses data collected from a larger project aimed to pilot HIV rapid testing in Tallinn, Estonia in 2008. The Tallinn Medical Research Ethics Committee approved this project. Data were collected by a self-administered 47-item study questionnaire, that was based on validated and widely used surveys of Family Health International (FHI), WHO and the United States Centers for Disease Control and Prevention (US CDC) for specific risk behaviour populations [6, 14-16]. The questionnaire was designed to collect data on three distinct domains: demographics, HIV risk behaviour knowledge and behavioral characteristics such as sexual orientation, substance use and condom use. Additionally, HIV rapid tests were conducted by study staff paid by the Estonian National Institute for Health Development. Anonymous results of the rapid HIV tests were linked to the questionnaire data using a unique identifier.

MSM were identified as men who self-identified their sexual orientation as either homosexual or bisexual. The study population of 79 MSM was recruited in Tallinn, Estonia, from AIDS counseling centers $(n=13)$, a low threshold needle exchange center $(n=5)$, a gay and lesbian information center $(n=8)$, a gay sauna $(n=22)$, and a gay bar $(n=31)$. The use of a convenience sample was in consensus with other recently published studies $[17,18]$. HIV risk behaviour knowledge was assessed through 13 questions about 
transmission, social perception and treatment (see Table 2). One point was awarded for each correct answer and the total knowledge score was calculated summing up the correct answers. Alcohol consumption was assessed by number of cans, bottles, glasses and shots of standard alcoholic drinks such as beer, cider, wine and strong alcoholic drinks, consumed by the participant in seven days prior to the survey. Participants also reported consumption of alcohol during four weeks preceding the survey, using the following categories: everyday, more than once per week, once per week or never. Characteristics of drug use were assessed by questions asking

TA B L E 1

Characteristics of study participants, Tallinn, Estonia, $2008(\mathbf{n}=79)$ a, b

\begin{tabular}{|c|c|c|c|c|}
\hline & \multicolumn{3}{|c|}{ Data by age group } & \multirow[t]{2}{*}{ All } \\
\hline & $\begin{array}{c}18-25 \text { years } \\
n(\%)\end{array}$ & $\begin{array}{c}26-35 \text { years } \\
n(\%)\end{array}$ & $\begin{array}{c}>35 \text { years } \\
n(\%)\end{array}$ & \\
\hline \multicolumn{5}{|l|}{ Ethnicity } \\
\hline Estonian & $16(76)$ & $18(58)$ & $19(83)$ & $53(71)$ \\
\hline Russian & $5(24)$ & $9(29)$ & $2(9)$ & $16(21)$ \\
\hline Others & 0 & $4(13)$ & $2(9)$ & $6(8)$ \\
\hline \multicolumn{5}{|l|}{ Level of education } \\
\hline Less than secondary & $4(19)$ & $2(7)$ & $3(14)$ & $9(13)$ \\
\hline Secondary & $7(33)$ & $3(10)$ & $3(14)$ & $13(18)$ \\
\hline Vocational & $3(14)$ & $7(24)$ & $3(14)$ & $13(18)$ \\
\hline Post-secondary & $7(33)$ & $17(59)$ & $12(57)$ & $36(51)$ \\
\hline \multicolumn{5}{|l|}{ Income $^{*}$} \\
\hline$\leq 7,500$ EEK per year & $13(68)$ & $6(21)$ & $4(20)$ & $23(34)$ \\
\hline > 7,501 EEK per year & $6(14)$ & $23(79)$ & $16(80)$ & $45(66)$ \\
\hline \multicolumn{5}{|l|}{ Sexual orientation } \\
\hline Homosexual & $13(62)$ & $17(55)$ & $11(48)$ & $41(55)$ \\
\hline Bisexual & $8(38)$ & $14(45)$ & $12(52)$ & $34(45)$ \\
\hline \multicolumn{5}{|l|}{ HIV knowledge score } \\
\hline (13 points max.) & $10.5( \pm 1.5)^{c}$ & $10.48( \pm 1.8)^{c}$ & $10.0( \pm 1.7)^{c}$ & $10.4( \pm 1.7)^{c}$ \\
\hline \multicolumn{5}{|c|}{ Standard alcohol drinks in last week } \\
\hline & $5.8( \pm 6.3)^{c}$ & $8.0( \pm 8.2)^{c}$ & $5.6( \pm 3.8)^{\mathrm{c}}$ & $7.1( \pm 6.8)^{\mathrm{c}}$ \\
\hline \multicolumn{5}{|c|}{ Alcoholic drinks in last month } \\
\hline None & 0 & $3(10)$ & $1(4)$ & $4(6)$ \\
\hline 1 or less per week & $11(55)$ & $13(45)$ & $11(48)$ & $35(49)$ \\
\hline$>1$ per week & $8(40)$ & $13(45)$ & $9(39)$ & $30(42)$ \\
\hline Everyday & $1(5)$ & 0 & $2(4)$ & $3(4)$ \\
\hline \multicolumn{5}{|l|}{ Illicit drug use* } \\
\hline No & $9(43)$ & $15(50)$ & $18(78)$ & $42(57)$ \\
\hline Not regular & $11(52)$ & $11(37)$ & $5(22)$ & $27(37)$ \\
\hline Frequent/regular & $1(5)$ & $4(13)$ & 0 & $5(7)$ \\
\hline \multicolumn{5}{|c|}{ Condom used in last intercourse } \\
\hline Yes & $12(57)$ & $14(48)$ & $14(64)$ & $40(56)$ \\
\hline No & $9(43)$ & $15(52)$ & $8(36)$ & $32(44)$ \\
\hline \multicolumn{5}{|c|}{ Condom use in last 12 months } \\
\hline Regular & $9(47)$ & $14(45)$ & $12(63)$ & $35(51)$ \\
\hline Sometimes & $5(26)$ & $13(42)$ & $4(21)$ & $22(32)$ \\
\hline Never & $5(26)$ & $4(13)$ & $3(16)$ & $12(17)$ \\
\hline \multicolumn{5}{|l|}{ Previous HIV test ${ }^{\star}$} \\
\hline No & $13(62)$ & $5(16)$ & $6(29)$ & $24(33)$ \\
\hline Yes & $8(38)$ & $26(84)$ & $15(71)$ & $49(67)$ \\
\hline
\end{tabular}

EEK: Estonian Kroons; SD: standard deviation

a chi-squared test for categorical variables and Mann-Whitney test for continuous variable. Fisher's exact test was used if any individual cell in crosstabulation had less than five observations

b numbers do not always add up to 79 due to missing values, only available data reported; percentages may not add up to $100 \%$ due to rounding

${ }^{c}$ mean $( \pm S D)$

* Indicate significant differences $(p<0.05)$ among age groups 
about the mode of drug use (pills, injecting, inhaling, smoking, mixed in food/drink), type of drugs used (amphetamine, heroin, cocaine, marijuana, ecstasy, China White and others), and frequency of drug use (every day, frequently, occasionally). Participants were asked about history of sexually transmitted infections (STI) in the past 12 months before the survey and whether they were previously tested for HIV and result from it. Demographic data were collected, such as age, sex, level of education, ethnicity and monthly income (Table 1).

\section{Statistical Analyses}

Descriptive and exploratory analyses were done by chi-squared test for categorical variables and Mann-Whitney test for continuous variables. Fisher's exact test was used if any individual cell in cross-tabulations had less than five observations. Preliminary data analysis detected one outlier: a respondent reporting consumption of 140 drinks in seven days prior to the survey, whereas rest of the data ranged between 0-33 drinks. This observation was removed in further analyses for alcohol consumption. Univariate analysis of alcohol consumption in seven days prior to the survey indicated significant association with various socio-demographic and behavioral characteristics. Therefore, we further explored these relationships with a multivariable Poisson regression model, where total number of drinks consumed in seven days prior to the survey (count data with satisfactory normal distribution) was the response variable and socio-demographic and behavioural characteristics such as sexual orientation were predictor variables. In order to control for potential bias due to site of recruitment, this variable was included in the Poisson regression equation. Goodness-of-fit indicated a significant model with a statistically good fit $(\chi 2=$ 240.7; $p<0.001)$. Statistical significance was set at $\alpha \leq 0.05$ and a two-sided $p$ value or $95 \%$ confidence intervals $(\mathrm{Cl})$ are reported for the corresponding analysis. Stata 10.0 was used for statistical analyses (StataCorp LP. College Station, TX).

\section{Results}

\section{Characteristics of participants}

The mean age of the participants was 32 years (SD \pm 11 ), with most participants between 25 and 35 years of age (median age,
30, range 18-62). More than a quarter of the sample was of nonEstonian ethnicity: 16 (20\%) were Russian and 7 (9\%) were other (not defined). More than half of the participants $(n=38)$ reported a higher than secondary level education and 48 (67\%) reported a monthly income of more than 7,500 Estonian kroons (EEK). In Tallinn, according to the national statistics, 2008, the net average monthly wage was about 11,800 EEK (668 Euros) and median monthly income was about 7,500 EEK (480 Euros) [19]. Less than half of the men $(n=35 ; 44 \%)$ reported bisexual orientation. There were no significant differences in sexual orientation by age group, ethnicity, level of education and monthly income. The mean age of anal or vaginal sexual debut in the sample was 17.6 (SD \pm 3.7 ) years. Mean age at sexual debut was statistically higher in homosexual men compared to bisexual men (18.4 vs. 16.3 years; p-value $=0.04)$. Table 1 presents participant characteristics by age group.

More than two-thirds of the participants $(n=52 ; 68 \%)$ were tested previously for HIV. Of these, eight men were aged 18-25 years, compared with 26 aged $26-35$ years and 15 aged $>35$ years ( $p$-value $<0.01$ ). Uptake of previous HIV testing did not show statistically significant differences by ethnicity, level of education, monthly income and sexual orientation. Of the 25 participants who were not tested previously, 12 reported not considering getting tested, seven reported not having had an opportunity, and seven stated that they had had no time for taking the test. Of the two men who tested HIV-positive from the rapid test, one was detected during the study rapid testing and the other was tested before our study. Six participants reported having had STI in the previous 12 months.

\section{HIV risk behavior knowledge and socio-demographic \\ characteristics}

The median score for HIV related knowledge was 11 points. Only six men answered all 13 questions correctly. The total number of correct answers did not differ significantly by socio-demographic characteristics. The participant responses to HIV risk behavior questions are presented in Table 2. Least correctly answered statements were: "Does washing the genitals after sex protect from

T A B L E 2

Assessment of HIV risk behavior knowledge, Tallinn, Estonia, $2008(\mathbf{n}=79)^{\mathrm{a}}$

\begin{tabular}{|c|c|c|c|c|}
\hline & Questions & $\begin{array}{c}\text { Correct } \\
n(\%)\end{array}$ & $\begin{array}{l}\text { Wrong } \\
n(\%)\end{array}$ & $\begin{array}{c}\text { Not sure } \\
n(\%)\end{array}$ \\
\hline 1 & Can using a condom correctly prevent HIV? & $68(88)$ & $5(7)$ & $4(5)$ \\
\hline 2 & Can a person get HIV from mosquitoes? & $64(81)$ & $7(9)$ & $8(10)$ \\
\hline 3 & Can a person get HIV from sharing a meal with someone with HIV? & $75(95)$ & $2(3)$ & $2(3)$ \\
\hline 4 & Can a person get HIV from sharing a needle or works from someone with HIV? & 78 (99) & $1(1)$ & 0 \\
\hline 5 & Can you tell if a person has HIV by looking at them? & $64(81)$ & $3(4)$ & $12(16)$ \\
\hline 6 & Do birth control pills protect from HIV? & $68(88)$ & $1(1)$ & $8(10)$ \\
\hline 7 & Getting a tattoo/piercing by a non-licensed person increases the risk of contracting HIV. & $67(85)$ & $11(14)$ & $1(1)$ \\
\hline 8 & Can a pregnant woman with HIV transmit HIV to her child? & $64(81)$ & $4(5)$ & $11(14)$ \\
\hline 9 & Can breastfeeding children get HIV from an HIV infected mother? & $38(51)$ & $11(15)$ & $26(35)$ \\
\hline 10 & Does washing the genitals after sex protect from HIV? & $51(66)$ & $10(13)$ & $16(21)$ \\
\hline 11 & Does pulling out interrupted intercourse before orgasm protect against HIV? & $55(71)$ & $11(14)$ & $11(14)$ \\
\hline 12 & If you are HIV positive, can you get treatment? & $49(65)$ & $7(9)$ & $20(26)$ \\
\hline 13 & Do HIV medications improve the quality of life for people with HIV? & $53(68)$ & $10(13)$ & $15(19)$ \\
\hline
\end{tabular}


HIV?"; "Does pulling out interrupted intercourse before orgasm protect against HIV?"; "Can breastfeeding children get HIV from an HIV infected mother?"; "If you are HIV positive, can you get treatment?" and "Do HIV medications improve the quality of life for people with HIV?".

We further assessed the association of socio-demographic and behavioral characteristics with the range of knowledge about HIV risk behavior by the Fisher's exact test. With regards to ethnicity, the misconception that pulling out before orgasm protects against HIV was statistically significant higher among ethnic Russians than ethnic Estonians or other ethnicities ( $p$-value $=0.03$ ). Statistically significant differences were observed in the HIV/AIDS knowledge by level of education. Less than secondary school education was associated with higher proportion of wrong or 'not sure' answers. For example, two out of 10 men with less than secondary education reported 'not sure' about HIV transmission through sharing meals compared to none among those with higher than secondary education ( $p$-value $<0.01$ ). No significant differences were observed in HIV knowledge with regards to income, age categories, sexual orientation and site of recruitment.

\section{Substance use}

Nearly all participants $(n=72)$ reported having consumed alcohol in the four weeks prior to the survey, 32 had consumed more than one drink per week and five reported having consumed daily. Reported patterns of monthly consumption did not differ statistically significant by characteristics of participants. We also assessed the number of standard alcoholic drinks consumed in the week before the survey. Mean consumption was 7.1 drinks (SD \pm 6.8 ; median $=5$ ). Poisson regression analyses explored the association of the number of drinks consumed with socio-demographic and behavioral characteristics. After adjusting for other variables in the multivariable model, results showed a significant independent association of the rate of mean number of drinks consumed in seven days before the survey with education, age group, illicit drug use and sexual orientation. The rate of consumption was significantly lower in those with a higher education - vocational education (RR 0.26 ; $95 \% \mathrm{Cl} 0.16-0.42$ ) or post-secondary education (RR 0.48 ; $95 \% \mathrm{Cl}$ 0.33-0.69) compared to less than secondary education. Whereas, the rate was significantly higher in 26-35 years old men (RR 1.92; 95\% Cl 1.35-2.73) as compared to youngest age group (18-25 years); in those who reported 'not frequent' use of drugs (RR 1.73; 95\% Cl 1.38-2.16) and 'regular use' of drugs (RR 2.02; $95 \% \mathrm{Cl} 1.12-3.62$ ) as compared to those who reported 'no use ever'; and in those who reported homosexual orientation (RR $1.61 ; 95 \% \mathrm{Cl} 1.27-2.06)$ as compared to bisexual orientation.

Thirty-four of the 79 men (46\%) in our study reported some illicit drug use, the majority $(n=29)$ 'not frequent' users. More than half (12 out of 21 ) in the 18-25 years age group reported drug use compared to five out 23 participants older than 35 years ( $p$-value $=0.05)$. Fisher's exact test showed significant differences ( $p$-value $=0.02$ ) in drug use by ethnicity: 11 of the 16 Russian ethnic participants used illicit drugs compared with 20 out of 54 Estonians. No significant differences were observed with regards to level of education, monthly income and sexual orientation. Among the 34 participants who used illicit drugs, most commonly used drugs (some participants used more than one drugs), were amphetamines ( 11 cases), marijuana ( 11 cases), cocaine ( 6 cases), China White or White Persian (3 cases), ecstasy (8 cases), and eight cases for other or unknown drugs. Injecting drug use was reported by five men in our sample.

\section{Unprotected sex}

About half $(n=37)$ of the men did not use condoms regularly over last 12 months, of which 13 men reported never using condoms. A higher proportion of men with less than secondary education reported never using condoms (4 out of 7 ) compared to those with higher than secondary levels of education (3 out of 38). Differences however, fell little short of statistical significance ( $p$-value $=0.08$ ). No significant differences were observed by ethnicity, monthly income, age group category, sexual orientation and substance use.

A condom was not used during last sexual intercourse by 35 of the 79 men (46\%) in our study group. We assessed the association between condom use during last intercourse and number of alcoholic drinks in the week before the survey. Higher alcohol consumption was negatively associated with use of condom during the last intercourse (RR 0.48; 95\% Cl 0.41-0.56). No other significant differences were observed with regards to sociodemographic characteristics, sexual orientation and illicit drug use.

\section{Discussion and conclusion}

Our results show that about half of the 79 men participating in our study answered correctly for more than 10 out of 13 questions/ statements about HIV transmission and risk behavior. Similar findings were reported in an internet based survey conducted in spring 2004 and autumn 2005, by the Estonian Gay League and the National Institute of Health and Development (NIHD) [16, 20]. However, we found significant differences in the range of HIV risk behavior knowledge. Whereas, the majority of the men knew about prevention of HIV by correct use of condom or that HIV could be transmitted through sharing needles, a lower proportion of men could answer correctly about the fact that pulling out before orgasm or washing genitals after sex does not prevent HIV, that HIV could be transmitted to babies through breast-feeding, and that HIV treatment is available to all in Estonia, and it may improve quality of life. Our results indicated that HIV risk behavior knowledge may vary by socio-demographic factors such as education and ethnicity. Other studies in the geographical region have shown similar differences in HIV knowledge [21]. In a study by Kelly et al., on MSM in St. Petersburg, Russia, only $4 \%$ bisexual male participants were able to answer correctly to all the questions on HIV risk behavior knowledge; and $54 \%$ of the participants believed that washing carefully after sex protects against HIV [22].

We found that lower education, belonging to age group 2535 years, using illicit drugs and homosexual orientation were significantly associated with higher rate of consumption of alcohol over past seven days. About half of the men used illicit drugs, although most where non-frequent users. Moreover, illicit drug use was found to be higher among Russian men and the youngest age group (18-25 years). Higher level alcohol consumption among MSM has been indicated in other regional studies [17, 23]. In a study based in Zagreb, Croatia, Stulhofer et al. reported that more than third of the MSM participants used illicit drugs before having sex in the 12 months before the survey and more than half consumed alcohol before sex over the same period. Higher alcohol and substance use has been shown to increase overall risk of HIV transmission [24, 25]; therefore it is important to consider the socio-demographic differences in substance use among MSM in Estonia for directing HIV public health interventions.

In our study, about half of the men did not use condoms regularly in the 12 months before the survey and a similar proportion reported not using condoms during the last sexual intercourse. 
Lower education and high rates of alcohol consumption were found to be negatively associated with condom use. However, since we did not know whether the last intercourse was with a regular or a casual partner and the number of concurrent partners, interpretation of these results warrant caution. Nevertheless, other regional studies have indicated that having casual partners is very common in MSM social networks [17, 21]. Overall, studies investigating the correlation of unprotected sex between men with socio-demographic and behavioral characteristics have given mixed results. In a recent study by Amirkhanian et al., results showed that more than half (56\%) of MSM participants, from Hungary and Russia, had the most recent unprotected anal sex with a casual partner and that condom use significantly depended on psychosocial factors [26]. A large study based in Denmark, by Cowan and Haff, concluded that in recent years there has been an increase in the frequency of unprotected sex in MSM despite high level knowledge about HIV [27]. Stulhofer et al. however, found no relation between alcohol and drug use before sex and condom use over the last 12 months or during last anal sex [18]. Further investigation is warranted to understand the reasons for these mixed findings.

Our research has several limitations. We used a convenience sample, which limits the ability to represent the population, and could potentially bias some behavioral characteristics, such as alcohol use in men recruited from gay bars. Information about sexual partners of the participants, regular or casual, as well as the number of concurrent sexual partners, was not available, and therefore the results could not be adjusted for number of (casual) sex partners. The sample size was small and moreover, data presented in these analyses are self-reported, which resulted in missing data on some questions.

Despite these limitations we conclude that, socio-demographic and behavioral characteristics affect knowledge of HIV transmission, sexual risk behavior and substance use among MSM in Estonia and need to be taken into account for targeted intervention towards HIV prevention. Further research is needed to understand the complex association of HIV risk taking behavior and substance use among MSM.

\section{References}

1. Joint United Nations Programme on HIVIAIDS (UNAIDS) and World Health Organization (WHO). AIDS Epidemic Update December 2007. Geneva: UNAIDS/ WHO; 2007. Available from: http://data.unaids.org/pub/EPISlides/2007/2007_ epiupdate_en.pdf

2. European Centre for Disease Prevention and Control / WHO Regional Office for Europe: HIVIAIDS Surveillance in Europe 2007. Stockholm: European Centre for Disease Prevention and Control; 2008. Available from: http://ecdc.europa.eu/ en/publications/Publications/0812_SUR_HIV_AIDS_surveillance_in_Europe.pdf

3. van de Laar MJ, Likatavicius G, Stengaard AR, Donoghoe MC. HIV/AIDS surveillance in Europe: update 2007. Euro Surveill, 2008;13(50).pii=19066. Available from: http://www.eurosurveillance.org/ViewArticle.aspx?ArticleId=19066

4. Joint United Nations Programme on HIV/AIDS (UNAIDS) and World Health Organization (WHO). Epidemiological Fact Sheet on HIV/AIDS. Core data on epidemiology and response. Estonia, 2008. Geneva: UNAIDS/WHO; 2008. Available from: http://apps.who.int/globalatlas/predefinedReports/EFS2008/ full/EFS2008_EE.pdf

5. Trummal A, Lõhmus L, Rüütel K. Fighting HIV in Estonia in 2006 and 2007. Tallinn: Estonian National Institute for Health Development; 2008. Available from: http://www.tai.ee/failid/Fighting_HIV_in_Estonia_2006_2007.pdf

6. Lai T, Rätsep M, Rüütel K, Trummal A, Kahur K, Nielsen, et al. Modelling Estonia's concentrated HIV epidemic: a case study. Estonian National Institute of Health Development, Estonian Ministry of Social Affairs, WHO Regional Office for Europe. Copenhagen: WHO; 2009. Available from: http://www.who. it/Document/SHA/EST_HIV_EPI_rep.pdf
7. Joint United Nations Programme on HIV/AIDS (UNAIDS) and World Health Organization (WHO). Eastern Europe and Central Asia: AIDS epidemic update: regional summary. Geneva: UNAIDS; 2008. Available from: http://data.unaids. org/pub/Report/2008/jc1529_epibriefs_eeurope_casia_en.pdf

8. Blystad H, Nilsen Ö, Aavitsland P. Increase in reported HIV infections among MSM in Oslo, Norway. Euro Surveill. 2004;8(11).pii=2405. Available from: http:// www.eurosurveillance.org/ViewArticle.aspx?ArticleId=2405

9. Gebhardt M., Recent trends in new diagnoses of HIV infections in Switzerland: probable increase in MSM despite an overall decrease. Euro Surveill. 2005;10(12): pij=2850. Available from: http://www.eurosurveillance.org/ ViewArticle.aspx?ArticleId $=2850$

10. van de Laar MJ, Likatavicius G, Stengaard AR, Donoghoe MC. HIV/AIDS surveillance in Europe: update 2007. Euro Surveill, 2008:13(50).pii=19066. Available from: http://www.eurosurveillance.org/ViewArticle. aspx?ArticleId=19066

11. Amirkhanian YA, Kelly JA, Kirsanova AV, DiFranceisco W, Khoursine RA, Semenov AV, et al. HIV risk behaviour patterns, predictors, and sexually transmitted disease prevalence in the social networks of young men who have sex with men in St Petersburg,

12. Preston DB, D'Augelli AR, Kassab CD, Cain RE, Schulze FW, Starks MT. The relationship of stigma to the sexual risk behaviors of rural men who have sex with men. AIDS Educ Prev. 2007;19(3): 291-303.

13. Trummal A, Lõhmus L, HIV/AIDS Prevention in Estonia in 2004 - 2005. Tallinn: Estonian National Institute for Health Development; 2006. Available from: http://www.tai.ee/failid/HIV_prevention_in_Estonia_2004_2005_09.2006.pdf

14. Amon J, Brown T, Hogle J, NacNeil J, Magnani R, Mills S, et al. Behavioral Surveillance Surveys (BSS): Guidelines for Repeated Behavioral Surveys in Populations at Risk of HIV. 2000; Family Health International. Available from: http://www.fhi.org/NR/rdonlyres/ezcscxathg cvhxzmwxjlfgkl4mezcmep6ogzqty3lbyf5ighmb6k2swbgar32xup6yh5sykj6ii2kwp/ bssguidelinesfullenhv.pdf

15. Sanchez T, Finlayson T, Drake A, Behel S, Cribbin M, Dinenno E, et al. Human immunodeficiency virus (HIV) risk, prevention, and testing behaviors--United States, National HIV Behavioral Surveillance System: men who have sex with men, November 2003-April 2005. MMWR Surveill Summ. 2006;55(6):1-16.

16. Trummal A, Lõhmus L, HIV/AIDS Prevention in Estonia in 2004 - 2005. Tallinn: Estonian National Institute for Health Development; 2006 [p.1-67]. Available from: http://www.tai.ee/failid/HIV_prevention_in_Estonia_2004_2005_09.2006. pdf

17. Amirkhanian YA, Kelly JA, Kukharsky AA, Borodkina OI, Granskaya JV, Dyatlov RV, et al. Predictors of HIV risk behavior among Russian men who have sex with men: an emerging epidemic. AIDS. 2001;15(3):407-12.

18. Stulhofer A, Baćak V, Bozicević I, Begovac J. HIV-related sexual risk taking among HIV-negative men who have sex with men in Zagreb, Croatia. AIDS Behav. 2008;12(3):505-12

19. Statistics Estonia. 2009 [cited 200930 November]; Available from: http:/ www.stat.ee/wages-and-salaries-and-labour-costs.

20. Rüütel K, Uusküla A. HIV epidemic in Estonia in the third decade of the AIDS era. Scand J Infect Dis. 2006;38(3):181-6.

21. Longfield K, Astatke H, Smith R, McPeak G, Ayers J. Men who have sex with men in Southeastern Europe: Underground and at increased risk for HIV/STIs. Cult Health Sex. 2007; 9(5):473-87.

22. Kelly JA et al., HIV risk characteristics and prevention needs in a community sample of bisexual men in St. Petersburg, Russia. AIDS Care. 2002;14(1):63-76.

23. Csepe P, Amirkhanian YA, Kelly JA, McAuliffe TL, Mocsonoki L. HIV risk behaviour among gay and bisexual men in Budapest, Hungary. Int J STD AIDS. 2002;13(3):192-200.

24. Celentano DD, Valleroy LA, Sifakis F, MacKellar DA, Hylton J, Thiede H, et al. Associations between substance use and sexual risk among very young men who have sex with men. Sex Transm Dis. 2006;33(4):265-71.

25. Folch C, Esteve A, Zaragoza K, Muñoz R, Casabona J et al. Correlates of intensive alcohol and drug use in men who have sex with men in Catalonia, Spain. Eur J Public Health. 2009 Jun 29.

26. Amirkhanian YA, Kelly JA, Takacs J, Kuznetsova AV, DiFranceisco WJ, Mocsonaki L, et al. HIV/STD prevalence, risk behavior, and substance use patterns and predictors in Russian and Hungarian sociocentric social networks of men who have sex with men. AIDS Educ Prev. 2009;21(3):266-79.

27. Cowan SA, Haff J. HIV and risk behaviour among men who have sex with men in Denmark--the 2006 Sex Life Survey. Euro Surveill. 2008:13(48). pij=19050. Available from: http://www.eurosurveillance.org/ViewArticle. aspx?ArticleId=19050 